\title{
Evaluación de un péptido quimérico NS4/NS5 para la detección de anticuerpos contra VHC
}

\author{
Ivonne Gómez, Milenen Hernández, Carlos Martínez, Marleby García, Antonio Melchor \\ Centro de Inmunoensayo, Ciudad de La Habana, Cuba.
}

\begin{abstract}
Para el diagnóstico del virus de la hepatitis $\mathrm{C}$, se utilizan las pruebas de Elisa, debido a su sensibilidad y especificidad. Gran parte de estas pruebas se basa en el empleo de péptidos sintéticos y, en la actualidad, de péptidos quiméricos. En este estudio se sintetizó un péptido quimérico que comprende secuencias inmunodominantes de las regiones no estructurales NS4 y NS5 del virus de la hepatitis C. El péptido representativo de las dos secuencias está separado por un brazo espaciador de dos residuos de glicina. El péptido se evaluó como antígeno en un ensayo UMELISA, utilizando muestras positivas $(n=30)$, muestras negativas $(n=40)$ y el panel de Boston Biomedica Inc. $(n=40)$. Los resultados del péptido quimérico NS4/ NS5 se compararon con los resultados de los péptidos individuales NS4 y NS5 y con la mezcla de estos dos péptidos. Los resultados de los péptidos individuales coinciden con los datos informados en la literatura. Con la mezcla de los péptidos, no aumentó la detección de muestras positivas, pero con el péptido quimérico se logró aumentar la sensibilidad.
\end{abstract}

Palabras clave: péptidos sintéticos, péptidos quiméricos, VHC, NS4, NS5, UMELISA

\section{Evaluation of a chimeric peptide NS4 and NS5 for HCV antibody detection}

Elisa tests are widely used for the diagnosis of hepatitis $C$ virus infection because of their sensitivity and specificity. Most of the Elisas are based on the use of synthetic peptides. At present, chimeric peptides are being used. In the present study, a chimeric peptide with immunodominant sequences of the NS4 and NS5 nonstructural regions of the hepatitis C virus was synthesized. The representative peptide of the two sequences was separated by a glycineglycine spacer. The peptide was tested as antigen in an UMELISA assay, using positive samples $(n=30)$, negative samples $(n=40)$ and a panel from Boston Biomedica Inc. $(n=40)$. Results from the NS4 and NS5 chimeric peptide were compared with the results from the NS4 and NS5 individual peptides and with the mixture of these two peptides. Results of individual peptides coincide with those previously reported. The mixture of the two peptides did not increase the detection of positive samples, but the chimeric peptide increased sensitivity.

Key words: synthetic peptides, chimeric peptide, HCV, NS4, NS5, UMELISA

El virus de la hepatitis C (VHC), descubierto en 1989 , es el mayor agente causal de la hepatitis postransfusional en el mundo $(1,2)$. Tiene un genoma de ARN de cadena simple con sentido positivo de 9.500 nucleótidos (9,4 kilobases), aproximadamente, que codifica para una poliproteína de aproximadamente 3.000 aminoácidos, con elevado grado de heteroge-

Correspondencia:

iqpeptidos@cie.sld.cu

Recibido: 12/06/00; aceptado: 02/02/01 neidad genética y que se puede fragmentar en tres proteínas estructurales (C, E1 y E2/NS1) y seis no estructurales (NS2, NS3, NS4a, NS4b, NS5a y NS5b).

Su transmisión es parenteral $(60-70 \%$ de los casos), así como por transfusiones de sangre y por el uso de drogas intravenosas. En menor grado, se ha identificado por transmisión sexual, intrafamiliar y de madre a hijo. En el 30 a 40\% de los casos, no se han identificado los factores de riesgo (1). 
Para la detección de este virus, se utilizan ampliamente las pruebas de Elisa por las ventajas que reporta en cuanto a sensibilidad y especificidad (3). Estos ensayos se basan en la mezcla de péptidos sintéticos (4) y proteínas recombinantes de las regiones inmunodominantes del virus. En los últimos años, se están empleando en el diagnóstico péptidos quiméricos de diferentes regiones del virus (5).

En este trabajo, se sintetizaron péptidos inmunodominantes de las regiones no estructurales NS4 y NS5, así como un péptido quimérico que comprende ambas regiones unidas por un brazo espaciador glicina-glicina. Se presentan los resultados comparativos de ese péptido quimérico con los péptidos individuales.

\section{Materiales y métodos}

\section{Síntesis de péptidos}

Con el empleo de la predicción de los determinantes antigénicos de las proteínas $(1,6)$, se sintetizaron tres péptidos representativos del virus de la hepatitis C. Los péptidos NS4 de 17 aminoácidos (1920-1950) y NS5 de 20 aminoácidos (2290-2330) representan secuencias inmunodominantes de las regiones no estructurales NS4 y NS5, respectivamente. El péptido NS4/NS5 comprende las secuencias de las dos regiones no estructurales, separadas por un brazo espaciador de dos glicinas. Los péptidos se sintetizaron en fase sólida por el método descrito por Merrifield en 1963, siguiendo la estrategia Bocen bolsas de polipropileno (Biotech. Instruments, USA) (7). Se utilizaron $100 \mathrm{mg}$ de la resina 4metilbencilhidrilamina (MBHA) (100-200 mesh, 1 $\mathrm{mmol} / \mathrm{g}$, Bachem) (8) y el grupo alfa-amino de los aminoácidos protegidos con el grupo Boc(Bachem, Suiza). Las reacciones de acoplamiento se realizaron por activación del grupo carboxilo de cada aminoácido con cantidades equivalentes de DIPCDI 0,2 mol// en diclorometano (DCM). La eficiencia del acoplamiento de los aminoácidos protegidos se verificó con ayuda del ensayo de ninhidrina. La protección temporal (Boc-) se eliminó con ácido trifluoracético a $37,5 \%$ en $\operatorname{DCM}(7,8)$. La desprotección final se hizo por el método lowhigh con ácido fluorhídrico (HF) puro para análisis (Fluka, Suiza) $(7,8)$. La extracción del péptido se hizo con ácido acético al $30 \%$ en agua destilada. El extracto final diluido en agua se liofilizó en una liofilizadora Edwards de tecnología inglesa de 9 $\mathrm{kg}$ de capacidad en el condensador.

\section{Caracterización de los péptidos sintéticos}

La determinación de la pureza de los péptidos sintéticos se hizo por el sistema HPLC (High Performance Liquid Chromatography), mediante cromatografía de fase reversa (RP-HPLC) (9), en la que se aplicaron $0,2 \mathrm{mg}$ de péptido (gradiente: 0-60\% B (33'); velocidad de flujo: $0,5 \mathrm{ml} / \mathrm{min}$; velocidad del papel: $2 \mathrm{~mm} / \mathrm{min}$; sensibilidad: 0,1 AUFS y temperatura: $22^{\circ} \mathrm{C}$ ). En los cromatogramas se observó una señal principal que se correspondía con la máxima actividad de los péptidos en el UMELISA. La caracterización del péptido quimérico se realizó mediante la espectrometría de masas MALDI-TOF (Matrix Assisted Laser Desorption of lons Time of Flight) (10) y el peso molecular coincidió con el peso molecular teórico.

\section{Recubrimiento de la fase sólida}

Con cada uno de los péptidos por separado, se preparó una disolución a $2 \mathrm{mg} / \mathrm{ml}$ en carbonatobicarbonato, 0,05 mol/l, $\mathrm{pH}$ 9,6. Como fase sólida, se emplearon placas de poliestireno irradiado (11) con capacidad para $30 \mathrm{ml}$ (placas UMELISA, Greiner labortechnik, Alemania), las que se recubrieron a $15 \mathrm{ml} /$ pocillo y se incubaron 4 horas a $37^{\circ} \mathrm{C}$. La placas se lavaron con una disolución amortiguadora de PBS-T ( $8 \mathrm{~g}$ de $\mathrm{NaCl} ; 1,215 \mathrm{~g}$ de $\mathrm{Na}_{2} \mathrm{HPO}_{4} \cdot 2 \mathrm{H}_{2} \mathrm{O} ; 0,2 \mathrm{~g}$ de $\mathrm{KH}_{2} \mathrm{PO}_{4} ; 0,2 \mathrm{~g}$ de $\mathrm{NaN}_{3}$; $0,5 \mathrm{~mL}$ de Tween-20 para un volumen de $1.000 \mathrm{ml}$ de agua destilada y $\mathrm{pH}$ de $7,3-7,5)$, y, posteriormente, se bloquearon con una disolución de preservo (sacarosa al $5 \%$ y BSA al $1 \%$ en PBSTween) durante toda la noche a temperatura ambiente $\left(20-25^{\circ} \mathrm{C}\right)$. Se aspiró la disolución de preservo y la fase sólida se dejó secar a $37^{\circ} \mathrm{C}$ durante 2 horas. Las placas recubiertas se conservaron a $4{ }^{\circ} \mathrm{C}$ en una cubierta protectora hasta el momento de su uso (1).

\section{Ensayo UMELISA}

Las muestras por evaluar se diluyeron 1:20 en suero de carnero al $5 \%$ en una disolución amortiguadora Tris- $\mathrm{HCl}$ ( $15 \mathrm{mmol} / \mathrm{l}$ de Tris; $\mathrm{pH} 7,8$ y $0,05 \%$ Tween-20) y se incubaron 30 minutos a 
$37^{\circ} \mathrm{C}$ en las placas de reacción. Se lavó tres veces con la disolución amortiguadora Tris- $\mathrm{HCl}$ para eliminar los componentes no fijados y se adicionó un conjugado anti-IgG humana en carnero marcada con fosfatasa alcalina (Böehringer Mannheim $\mathrm{GmbH}$, Alemania), que se incubó durante $30 \mathrm{~min}$ a $37^{\circ} \mathrm{C}$. Se realizó un nuevo lavado en las mismas condiciones y se añadió, entonces, el sustrato fluorigénico 4-metilumbeliferilfosfato (Koch Light Ltd. Haverhill, Suffolk, England), el cual se incubó durante 30 minutos a temperatura ambiente (12). La fluorescencia emitida fue medida en un fluorímetro de la serie SUMA ${ }^{\circledR}$ (PR-521, Centro de Inmunoensayo) (excitación a $365 \mathrm{~nm}$ y emisión a $450 \mathrm{~nm}$ ). En todos los experimentos se incluyeron controles positivos y negativos; los ensayos se realizaron por cuadriplicado y las muestras se analizaron por duplicado.

\section{Muestras}

Se analizaron muestras positivas de diferente procedencia $(n=30)$, confirmadas por el ensayo confirmatorio Deciscan HCV, muestras negativas $(n=40)$ y muestras pertenecientes a los paneles PVH103 (bajo título) y PVH204 (mixto) de Boston Biomedica Inc. $(\mathrm{n}=40)$.

\section{Parámetros de evaluación clínica}

Según estudios previos, se determinó como nivel de corte 0,3.

Se consideraron positivas todas las muestras donde (13):

$\begin{array}{ll}\frac{R}{N c}>1 & \text { donde: } \begin{array}{l}\text { Nc: nivel de corte } \\ \text { R: relación de corte } \\ \text { Fm: fluorescencia de } \\ \text { la muestra }\end{array} \\ \mathrm{R}=\frac{(\mathrm{Fm}-\mathrm{Xb})}{(\text { Fmenor }-\mathrm{Xb})} \times 0,3 \begin{array}{l}\mathrm{Xb} \text { : media del blanco } \\ \text { Fmenor: fluorescencia } \\ \text { menor del positivo }\end{array}\end{array}$

Entre los parámetros de evaluación clínica, se seleccionaron la sensibilidad y la especificidad, donde (13):

$$
\begin{aligned}
& \text { donde: } \\
& \mathrm{S}=\frac{\mathrm{VP}}{\mathrm{VP}+\mathrm{FN}} \times 100 \% \quad \begin{array}{c}
\mathrm{VP}: \begin{array}{c}
\text { verdaderos } \\
\text { positivos }
\end{array} \\
\mathrm{FN}: \begin{array}{c}
\text { falsos } \\
\text { negativos }
\end{array}
\end{array}
\end{aligned}
$$

$$
E=\frac{V N}{V N+F P} \times 100 \%
$$

\section{Resultados y discusión}

Se realizó la predicción de secuencias antigénicas de la región no estructural del VHC, basándonos en escalas de propensión para sitios antigénicos y para ello se empleó Microsoft Excel versión 7.0. De acuerdo con los resultados obtenidos, se realizó la síntesis en fase sólida de un péptido de la región no estructural (NS4) del VHC. El peso molecular teórico de este péptido fue de 2.208,73 kDa.

Empleando un ensayo UMELISA, se analizaron 28 muestras positivas a esta región (figura 1). El péptido NS4 se sintetizó de una zona que comprendía una secuencia similar a uno de los péptidos sintetizados por Deleys y colaboradores en 1992 (87\%); sin embargo, solamente se obtuvo $60,7 \%$ (17/28) de reactividad (14). Las 40 muestras informadas como negativas resultaron negativas en el ensayo (figura 1), lo cual implica $100 \%$ de especificidad. Los resultados de los valores de las muestras, tanto positivos como negativos, se muestran en el cuadro 1, considerándose positivas las muestras cuyos valores son superiores a 1 .

En 1995, Khudyakov y colaboradores (15) señalaron que en 20 péptidos de esta región encontraron reactividad antigénica en siete de ellos, siendo muy fuerte en cinco, en tanto que en cuatro observaron reconocimiento de la región 51-1 localizada en el antígeno c100-3.

Se analizó un total de 40 muestras de los paneles de Boston Biomedica Inc., 15 muestras del PVH103 (bajo título) y 25 muestras del PVH204; los resultados se muestran en el cuadro 2. Como referencia se emplearon los resultados de RIBA 3.0 .

Los resultados que se muestran en el cuadro 2 se repitieron en todos los ensayos realizados. Este péptido mostró baja reactividad $(37,5$ y $14,28 \%)$ frente a los paneles $\mathrm{PVH} 103$ y $\mathrm{PVH} 204$ en las condiciones de nuestro ensayo. Estos resultados coincidieron con lo informado porWang en 1991 (16). 
Muestras positivas

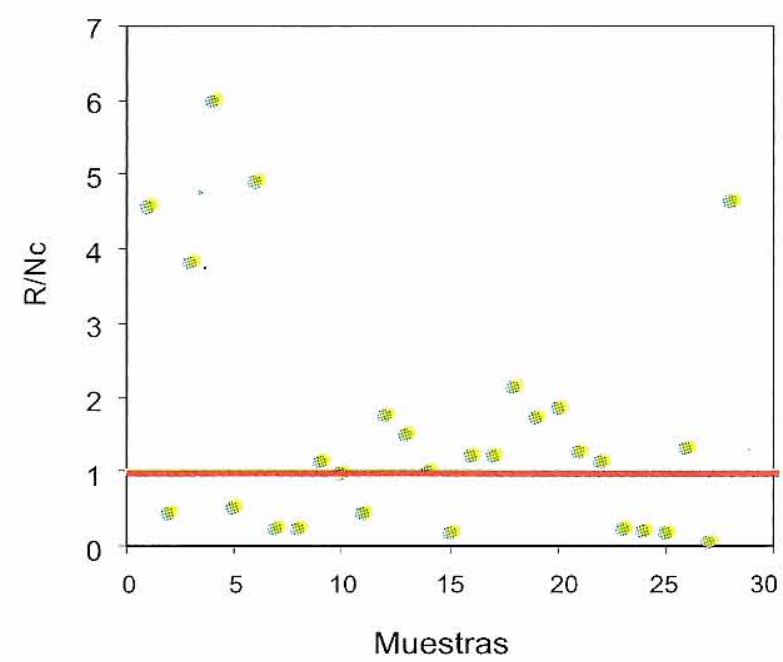

$\mathrm{R} / \mathrm{Nc}$ : relación sobre nivel de corte

Muestras: número de muestras analizadas

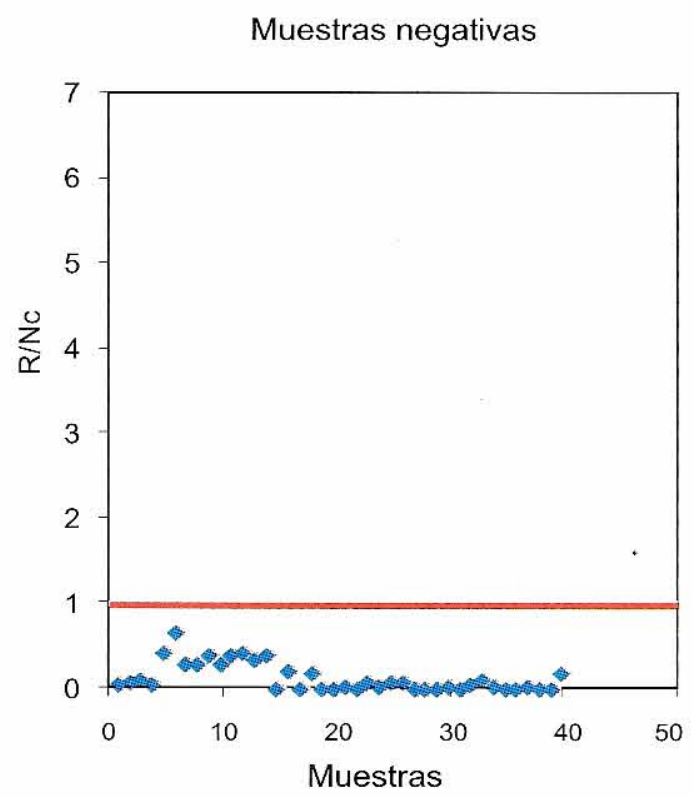

Figura 1. Resultados del péptido NS4 con muestras positivas y negativas.

La baja reactividad de este péptido de la región NS4 frente a las muestras positivas evaluadas puede deberse a que los anticuerpos de las muestras no reconozcan ninguno de los determinantes antigénicos presentes en el péptido NS4; a que los títulos de anticuerpos no sean lo suficientemente altos en correspondencia con la concentración del antígeno en fase sólida, o a que la disposición espacial de los determinantes antigénicos al unirse a la fase sólida no sea la adecuada y queden solapados.

Según el mismo procedimiento descrito para el péptido NS4 y a lo informado en la literatura, se realizó la síntesis en fase sólida de un péptido de la región no estructural (NS5) del HCV. El peso molecular teórico del péptido sintetizado fue de 2.288,93 kDa.

En el ensayo UMELISA, se analizaron 20 muestras positivas a esta región (figura 2). Para estas muestras, se obtuvo $81,25 \%$ de sensibilidad $(13 / 20)$. Las 40 muestras informadas como negativas resultaron negativas en el ensayo (figura 2), lo cual implica $100 \%$ de especificidad. Los resultados de los valores de las muestras, tanto positivos como negativos, se muestran en el cuadro 1; igualmente, se consideran positivas las muestras cuyos valores son superiores a 1 .

La secuencia de este péptido es similar a la reportada por Deleys y colaboradores en 1992 $(67 \%)(14)$.

La falta de reconocimiento de pocas muestras positivas por este péptido NS5 puede deberse, igualmente, a que los anticuerpos de las muestras no reconozcan ninguno de los determinantes antigénicos presentes en el péptido NS5; a que los títulos de anticuerpos no sean lo suficientemente altos en correspondencia con la concentración del antígeno en fase sólida, o a que la disposición espacial de los determinantes antigénicos al unirse a la fase sólida no sea la adecuada y queden solapados.

Se analizó un total de 40 muestras de los paneles de Boston Biomedica Inc., 15 muestras del PVH103 (bajo título) y 25 muestras del PVH204; los resultados se muestran en el cuadro 3. Como referencia, se emplearon los resultados de RIBA 3.0.

Estos paneles poseen muy pocas muestras positivas a la región NS5, y el péptido NS5 no es 
Cuadro 1. Resultados de las muestras negativas y positivas frente a cada uno de los péptidos.

\begin{tabular}{|c|c|c|c|c|c|c|c|c|}
\hline \multirow[b]{2}{*}{ Muestras } & \multicolumn{2}{|c|}{ NS4 } & \multicolumn{2}{|c|}{ NS5 } & \multicolumn{2}{|c|}{ NS4/NS5 } & \multicolumn{2}{|c|}{ Mezcla } \\
\hline & Negativas & Positivas & Negativas & Positivas & Negativas & Positivas & Negativas & Positivas \\
\hline 1 & 0,047 & 4,59 & 0,060 & 1,11 & 0,323 & 4,11 & 0,028 & 1,83 \\
\hline 2 & 0,067 & 0,46 & 0,070 & 1,34 & 0,040 & 3,65 & 0,218 & 2,94 \\
\hline 3 & 0,100 & 3,85 & 0,527 & 1,47 & 0,467 & 1,98 & 0,113 & 1,68 \\
\hline 4 & 0,043 & 6,02 & 0,577 & 0,59 & 0,167 & 5,42 & 0,233 & 0,94 \\
\hline 5 & 0,417 & 0,53 & 0,363 & 1,03 & 0,083 & 3,14 & 0,267 & 3,12 \\
\hline 6 & 0,653 & 4,92 & 0,574 & 0,57 & 0,873 & 1,65 & 0,345 & 1,09 \\
\hline 7 & 0,297 & 0,26 & 0,280 & 0,58 & 0,017 & 1,36 & 0,239 & 1,33 \\
\hline 8 & 0,283 & 0,26 & 0,053 & 5,43 & 0,690 & 1,16 & 0,098 & 0,89 \\
\hline 9 & 0,407 & 1,15 & 0,300 & 0,11 & 0,203 & 1,23 & 0,070 & 0,68 \\
\hline 10 & 0,287 & 1,02 & 0,270 & 6,45 & 0,167 & 0,50 & 0,034 & 1,01 \\
\hline 11 & 0,400 & 0,45 & 0,587 & 1,28 & 0,107 & 3,04 & 0,143 & 1,23 \\
\hline 12 & 0,437 & 1,77 & 0,637 & 1,20 & 0,130 & 2,78 & 0,187 & 2,39 \\
\hline 13 & 0,337 & 1,53 & 0,497 & 2,06 & 0,593 & 3,30 & 0,337 & 2,11 \\
\hline 14 & 0,407 & 1,04 & 0,892 & 5,33 & 0,113 & 1,26 & 0,038 & 0,84 \\
\hline 15 & 0,003 & 0,19 & 0,120 & 2,94 & 0,146 & 1,19 & 0,063 & 0,80 \\
\hline 16 & 0,210 & 1,24 & 0,343 & 3,00 & 0,187 & 2,79 & 0,180 & 1,74 \\
\hline 17 & 0,003 & 1,23 & 0,213 & 0,33 & 0,285 & 2,23 & 0,230 & 1,66 \\
\hline 18 & 0,190 & 2,17 & 0,330 & 0,27 & 0,197 & 3,68 & 0,250 & 1,91 \\
\hline 19 & 0,007 & 1,77 & 0,120 & 5,88 & 0,170 & 3,58 & 0,186 & 3,00 \\
\hline 20 & 0,003 & 1,90 & 0,057 & 0,33 & 0,197 & 3,69 & 0,107 & 2,97 \\
\hline 21 & 0,023 & 1,29 & 0,103 & 0,23 & 0,176 & 1,25 & 0,134 & 1,39 \\
\hline 22 & 0,003 & 1,16 & 0,003 & 0,39 & 0,143 & 1,27 & 0,186 & 1,00 \\
\hline 23 & 0,070 & 0,25 & 0,037 & 0,35 & 0,093 & 0,64 & 0,186 & 2,72 \\
\hline 24 & 0,023 & 0,23 & 0,090 & 0,33 & 0,193 & 1,42 & 0,210 & 2,95 \\
\hline 25 & 0,073 & 0,21 & 0,123 & 4,34 & 0,417 & 1,37 & 0,513 & 2,13 \\
\hline 26 & 0,080 & 1,35 & 0,020 & 0,18 & 0,587 & 2,45 & 0,623 & 1,71 \\
\hline 27 & 0,003 & 0,08 & 0,013 & 0,25 & 0,386 & 2,12 & 0,432 & 1,88 \\
\hline 28 & 0,003 & 4,68 & 0,003 & 0,32 & 0,653 & 1,20 & 0,597 & 0,92 \\
\hline 29 & 0,003 & 0,47 & 0,003 & 0,24 & 0,593 & 1,28 & 0,347 & 0,39 \\
\hline 30 & 0,027 & 0,12 & 0,030 & 0,38 & 0,432 & 0,15 & 0,303 & 0,41 \\
\hline 31 & 0,003 & 0,58 & 0,100 & 0,32 & 0,327 & 0,35 & 0,270 & 1,29 \\
\hline 32 & 0,057 & 0,23 & 0,097 & 0,43 & 0,132 & 0,17 & 0,170 & 3,51 \\
\hline 33 & 0,103 & 0,73 & 0,137 & 0,33 & 0,234 & 0,25 & 0,257 & 0,88 \\
\hline 34 & 0,020 & 0,20 & 0,053 & 0,32 & 0,312 & 0,36 & 0,187 & 1,38 \\
\hline 35 & 0,007 & 0,30 & 0,087 & 0,34 & 0,345 & 0,18 & 0,223 & 3,71 \\
\hline 36 & 0,003 & 0,64 & 0,037 & 0,35 & 0,329 & 0,25 & 0,210 & 2,49 \\
\hline 37 & 0,033 & 0,54 & 0,057 & 0,59 & 0,078 & 0,54 & 0,105 & 0,65 \\
\hline 38 & 0,003 & 0,22 & 0,047 & 1,03 & 0,057 & 0,13 & 0,064 & 0,97 \\
\hline 39 & 0,003 & 0,33 & 0,063 & 0,34 & 0,180 & 0,28 & 0,250 & 0,55 \\
\hline 40 & 0,187 & 0,19 & 0,137 & 0,29 & 0,403 & 0,29 & 0,237 & 0,38 \\
\hline 41 & & 0,26 & & 0,54 & & 0,17 & & 0,68 \\
\hline 42 & & 0,56 & & 0,47 & & 0,23 & & 4,85 \\
\hline 43 & & 0,65 & & 0,86 & & 0,14 & & 0,80 \\
\hline
\end{tabular}

capaz de detectar la única muestra positiva del panel PVH103, pero en el panel PVH204 tiene una buena reactividad $(85,71 \%)$. Estos resultados coincidieron nuevamente con lo informado para esta secuencia (14).

Debido a que los resultados obtenidos con el péptido NS4 no fueron los mejores y a que la alta reactividad antigénica de la región NS5 sugiere que puede ser significativa en el diagnóstico (15), se decidió sintetizar un péptido quimérico.

La síntesis se realizó mediante el método en fase sólida (7). Este péptido quimérico comprende las secuencias de NS4 y NS5 unidas mediante un brazo espaciador Gli-Gli (5). 
Muestras positivas

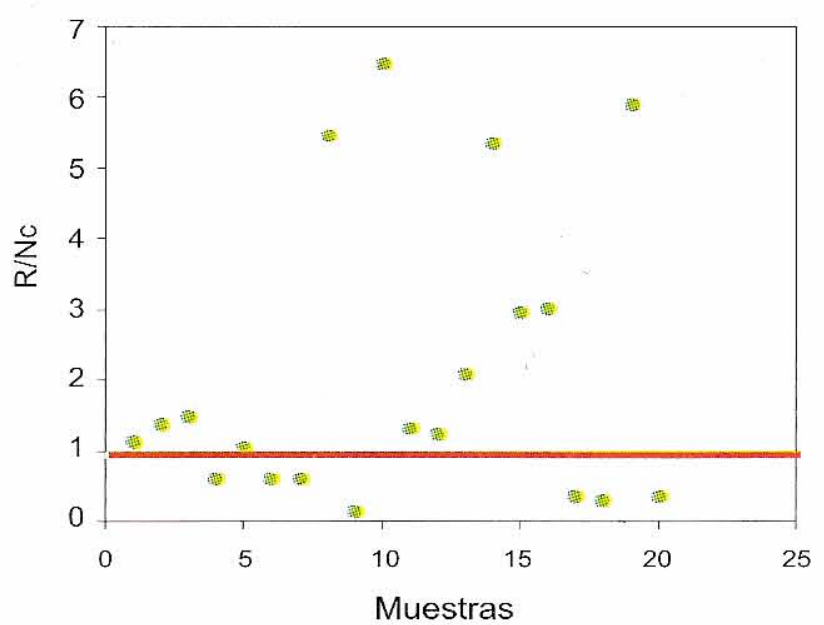

Muestras negativas

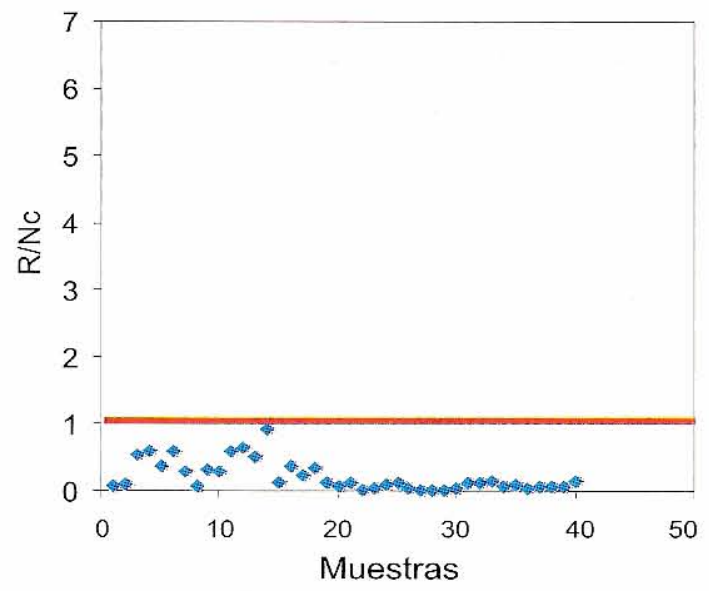

R/Nc: relación sobre nivel de corte

Muestras: número de muestras analizadas

Figura 2. Resultados del péptido NS5 con muestras positivas y negativas.

Cuadro 2. Resultados del péptido NS4 con las muestras de los paneles de la Boston Biomedica Inc.

\begin{tabular}{lcccc}
\hline & $\begin{array}{c}\text { Panel PVH103 } \\
\text { (bajo título) }\end{array}$ & $\begin{array}{c}\text { Panel PVH204 } \\
\text { (mixto) }\end{array}$ \\
Positivas & Negativas & Positivas & Negativas \\
\hline Muestras & $3 / 8$ & $7 / 7$ & $3 / 21$ & $4 / 4$ \\
Sensibilidad (\%) & 37,5 & - & 14,28 & - \\
Especificidad (\%) & - & 100 & - & 100 \\
\hline
\end{tabular}

Cuadro 3. Resultados del péptido NS5 con las muestras de los paneles de la Boston Biomedica Inc.

\begin{tabular}{lcccc}
\hline & $\begin{array}{c}\text { Panel PVH103 } \\
\text { (bajo título) }\end{array}$ & $\begin{array}{c}\text { Panel PVH204 } \\
\text { (mixto) }\end{array}$ \\
& Positivas & Negativas & Positivas & Negativas \\
\hline Muestras & $0 / 1$ & $14 / 14$ & $6 / 7$ & $18 / 18$ \\
Sensibilidad (\%) & 0 & - & 85,71 & - \\
Especificidad (\%) & - & 100 & - & 100 \\
\hline
\end{tabular}

La caracterización de este péptido fue por espectrometría de masas MALDI-TOF y el peso molecular que se obtuvo $(3.731,48 \mathrm{kDa})$ coincide con el valor teórico $(3.728,53 \mathrm{kDa})$.

Se realizó un estudio comparativo en el UMELISA empleando la mezcla de los péptidos individuales
(NS4 y NS5) y el quimérico (NS4/NS5), para lo cual se analizó un total de 30 muestras positivas, siendo 27 positivas a NS4, 20 a NS5 y 17 presentaron bandas a ambas regiones. Los resultados de los valores de las muestras, tanto positivos como negativos, se muestran en el cuadro 1; igualmente, se consideran positivas las muestras cuyos valores son superiores a 1. En la figura 3 se muestran los resultados de la mezcla, con un $73,3 \%$ de sensibilidad (22/30), y del péptido quimérico con una sensibilidad de $96,6 \%(28 / 30)$. La especificidad obtenida, tanto para la mezcla como para el quimérico, fue de $100 \%$, ya que todas las muestras negativas se comportaron como tal en el ensayo (figura 3).

Con la mezcla de los dos péptidos individuales (NS4 y NS5) y con el quimérico, se analizaron las 40 muestras de los paneles de Boston Biomedica Inc.; los resultados se muestran en el cuadro 4. Como referencia, se emplearon los resultados de RIBA 3.0.

Al analizar este péptido quimérico frente a los paneles de la Boston Biomedica Inc., se observó un aumento en la detección de muestras positivas, comparada con la de los péptidos individuales y con las mezclas de ellos. 
Muestras positivas

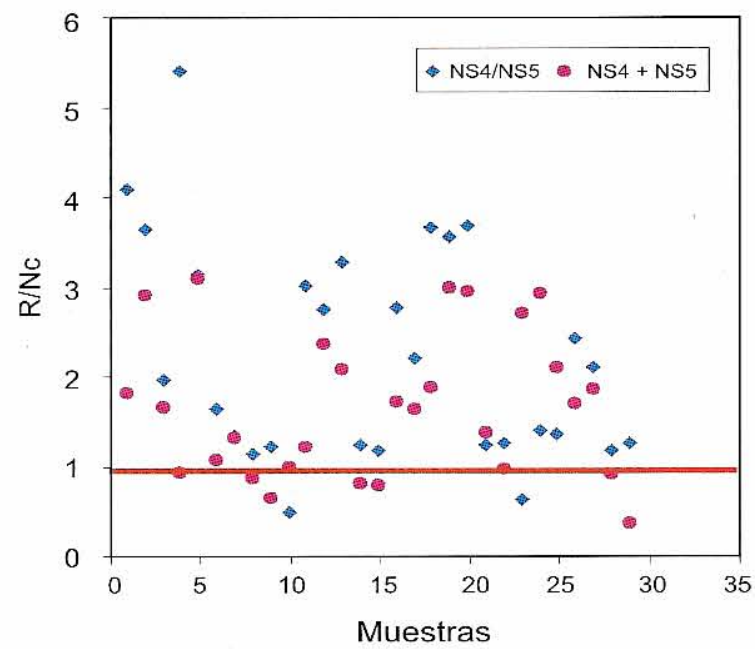

Muestras negativas

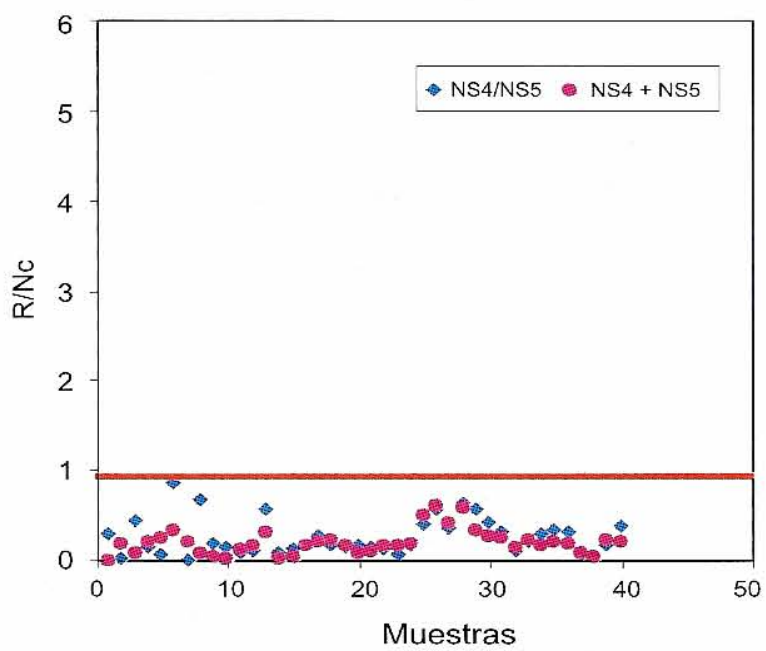

$\mathrm{R} / \mathrm{Nc}$ : relación sobre nivel de corte

Muestras: número de muestras analizadas

Figura 3. Resultados de la mezcla y del péptido quimérico con muestras negativas y positivas.

Cuadro 4. Resultados de la mezcla y del péptido quimérico con las muestras de los paneles de Boston Biomedica Inc.

\begin{tabular}{|c|c|c|c|c|c|c|c|c|}
\hline & \multicolumn{4}{|c|}{ Panel 103 (bajo título) } & \multicolumn{4}{|c|}{ Panel 204 (mixto) } \\
\hline & \multicolumn{2}{|c|}{ Positivas } & \multicolumn{2}{|c|}{ Negativas } & \multicolumn{2}{|c|}{ Positivas } & \multicolumn{2}{|c|}{ Negativas } \\
\hline & M & Q & M & $\mathbf{Q}$ & M & $\mathbf{Q}$ & M & $\mathbf{Q}$ \\
\hline Muestras & $4 / 9$ & $7 / 9$ & $6 / 6$ & $6 / 6$ & $10 / 21$ & $16 / 21$ & $4 / 4$ & $4 / 4$ \\
\hline Sensibilidad (\%) & 44,4 & 77,7 & - & - & 47,16 & 76,2 & - & - \\
\hline Especificidad (\%) & - & - & 100 & 100 & - & - & 100 & 100 \\
\hline
\end{tabular}

M: muestras; Q: péptido quimérico

Los resultados muestran que al sustituir los péptidos sintéticos individuales (NS4 y NS5) y la mezcla de éstos (NS4 + NS5) por el péptido quimérico (NS4/NS5), se detectan muestras positivas que anteriormente no se lograban detectar. Estos resultados coinciden con lo informado por Rosa y colaboradores en 1995. Además, la introducción de un brazo espaciador Gli-Gli no afecta la reactividad (5), ya que, incluso, se vió su aumento en el ensayo.

Estos péptidos quiméricos son ampliamente utilizados para la tipificación de los diferentes genotipos del VHC (5).

\section{Agradecimientos}

Al Departamento de Análisis Espectral del Instituto de Inmunología de Colombia por la colaboración prestada en la caracterización por espectrometría de masas de los péptidos sintetizados.

\section{Referencias}

1. Gómez I. Obtención y evaluación de péptidos sintéticos inmunodominantes de la región estructural y no estructural del virus de la hepatitis C (tesis). La Habana, Cuba: Universidad de La Habana; 1999.

2. Lunel F, Pawlotsky JM. Hepatitis C virus: virological diagnosis. Pathol Biol 1995;43:681-90. 
3. Yoshihara N. ELISA for diagnosis of infections by viruses. Nippon Rinsho 1995;53:2277-82.

4. Rosa C, Osborne SJ, Griva S, Garetto F, Bonelli F, Inventors Sorin Biomedica Italia, assignee. HCV peptides and uses thereof. European patent No. 0624597 A1. Mayo 2, 1994.

5. Rosa C, Caborne S, Garetto F, Griva S, Rivella A, Calabresi G, et al. Epitope mapping of the NS4 and NS5 gene products of hepatitis C virus and the use of a chimeric NS4-NS5 synthetic peptide for serodiagnosis. J Virol Methods 1995;55:219-32.

6. Chou PY, Fasman GD. Prediction of protein conformation. Biochemistry 1974;13:222-45.

7. Merrifield RB. Peptide synthesis. I. The synthesis of a tetropeptide. J Am Chem Soc 1963;85:2149-54.

8. Houghten RA. Simultaneous multiple peptide synthesis: the rapid preparation of large numbers of discretes peptides for biological, immunological and methodological studies. Biotechniques 1986;4:522-6.

9. Stone KL, LoPresti MB, Myron J, DeAngelis R, Williams KR. Enzymatic digestion of proteins and HPLC peptide isolation. En: A practical guide to protein and peptide purification for microsequencing. New York: Academic Press, Inc.; 1989. p.31-47.

10. Holle A, Mayer FJ. Matrix-Assisted Laser Desorption on the REFLEX ${ }^{\mathrm{TM}}$ Time of Flight Mass Spectrometry System. Mass Spectrometry 1993. p.18-20.
11. Boudet F, These J, Zouali M. UV-treated polystyrene microtitre plates for use in an ELISA to measure antibodies against synthetic peptides. J Immunol Methods 1991;142:73-82.

12. Gómez I, Cazanave J, Solís RL, Machado C, Bécquer D, Fernández JL. A new UMELISA format for the quantification of maternal serum alpha-fetoprotein. Biotecnología Aplicada 1996;13:109.

13. Broughton PMG, Bergonzi C, Lindstedt G, Loeber JG, Malan PG. Guidelines for the evaluation of diagnostic kits. General principles and outline procedures for the evaluation of kits for qualitative tests. Part 2. Paris: European Committee for Clinical Laboratory Standards; 1987.

14. Deleys RJ, Pollet D, Maertens G, Van Heuverswyn H, inventors; Innogenetics N.V., assignee. Synthetic antigens for the detection of antibodies to hepatitis $\mathrm{C}$ virus. US Patent No. 0489968 A1; 1992 March 16.

15. Khudyakov YE, Khudyakova NS, Jue DL, Lambert SB, Fang S, Fields HA. Linear B-cell epitopes of the NS3-NS4-NS5 proteins of the hepatitis $C$ virus as modeled with synthetic peptides. Virology 1995;206:666-72.

16. Wang CY, Inventor; United Biomedical Inc., assignee. Synthetic peptides specific for the detection of antibodies to HCV diagnosis of HCV infection and prevention thereof as vaccines. European Patent Application No. 0442394 A2; 1991 August 21. 